\title{
EPSL
}

Earth and Planetary Science Letters 139 (1996) $1-16$

\section{Modal depth anomalies from multibeam bathymetry: Is there a South Pacific superswell?}

\author{
Daniel A. Levitt, David T. Sandwell * \\ Scripps Institution of Oceanography, University of California at San Diego, Geological Research Division MC0215. 9500 Gilman Drive. \\ La Jolla, CA 92093-0902. USA
}

Received 12 April 1995; accepted 8 December 1995

\begin{abstract}
A region west of the southern East Pacific Rise (SEPR), between the Marquesas and Austral Fracture Zones has previously been found to exhibit anomalous depth-age behavior, based on gridded bathymetry and single-beam soundings. Since gridded bathymetry has been shown to be unsuitable for some geophysical analysis and since the area is characterized by unusually robust volcanism, the magnitude and regional extent of depth anomalies over the young eastem flank of the so called 'South Pacific Superswell' are re-examined using a mode-seeking estimation procedure on data obtained from several recent multibeam surveys. The modal technique estimates a representative seafloor depth, based on the assumption that bathymetry from non-edifice and edifice-populated seafloor has a low and a high standard deviation, respectively. Flat seafloor depth values are concentrated in a few bins which correspond to the mode. This method estimates a representative seafloor value even on seafloor for which more than $90 \%$ of coverage is dominated by ridge and seamount clusters, where the mean and median estimates may be shallow by hundreds of meters. Where volcanism-related bias is moderate, the mode, mean and median estimates are close.

Depth-age results indicate that there is only a small anomaly $(<200 \mathrm{~m})$ over $15-35$ Ma Pacific Plate seafloor with little age-dependent shallowing, suggesting that the lithosphere east of the main hot-spot locations on the 'superswell' is normal. An important implication is that, in sparsely surveyed areas, depths from ETOPO-5 are significantly different from true depths even at large scales $(\sim 1000 \mathrm{~km}$ ) and thus are unsuitable for investigations of anomalies associated with depth-age regressions. We find that seafloor slopes on conjugate profiles of the Pacific and Nazca Plates from 15 to $35 \mathrm{Ma}$ are both slightly lower than normal, but are within the global range. Proximate to the SEPR, seafloor slopes are very low (218 $\mathrm{m}$ $\mathrm{Myr}^{-1 / 2}$ ) on the Pacific Plate (0-22 Ma) and slightly high ( $410 \mathrm{~m} \mathrm{Myr}^{-1 / 2}$ ) on the Nazca Plate (0-8 Ma); slopes for older Pacific seafloor (22-37 Ma) are near normal (399 $\mathrm{m} \mathrm{Myr}^{-1 / 2}$ ). Seafloor slopes are even lower north of the Marquesas Fracture Zone but are highly influenced by the Marquesas Swell. We find that the low subsidence rate on young Pacific seafloor cannot be explained by a local hot-spot or a small-scale convective model exclusively and a stretching/thickening model requires implausible crustal thickness variation $(\sim 30 \%)$.
\end{abstract}

Keywords: South Pacific; superswells; multichannel methods; bathymetry; hot spots

\footnotetext{
•E-mail: dsandwell@ucsd.edu
} 


\section{Introduction}

A fundamental principal of the plate tectonics paradigm is that the depth of ocean floor is controlled by the thermal evolution of a boundary layer, the lithosphere, as it is transported from the mid-oceanic ridge [1]. Two primary types of models have evolved to describe the relation between lithospheric cooling and contraction and the observed monotonic decrease of heat flow and increase of basement depth with crustal age [2]. In the half space model [3,4], the lithosphere is the cold upper boundary layer of a cooling half space, so that depth and heat flow vary with an age $e^{1 / 2}$ and age ${ }^{-1 / 2}$, respectively. In the plate model [5,6] lithosphere is treated as a cooling plate with an isothermal lower boundary. Due to additional heat input to the base of the lithosphere by hot-spots [7] or by some type of small-scale convection [8] the depth and heat flow curves flatten out with age with a best-fitting asymptotic old-age plate thickness of $125 \mathrm{~km}$ and a basal temperature of $1350^{\circ} \mathrm{C}[9]$.

Over the past 20 years attention has focused on depth anomalies, those areas of the seafloor which have shown departure from the expected depth for a given age [10]. Several investigators have noted a correlation between broad, anomalously shallow regions, termed swells, and the location of prolific, hot-spot-related volcanism [1]-16]. For the majority of mid-plate swells, the presence of positive geoid and gravity anomalies suggest that a large part of the swell topography is compensated by thermally rejuvenated lithosphere [15].

In a seminal paper, McNutt and Fischer [17] advanced the superswell hypothesis in order to reconcile a number of unique observations in the south-central Pacific which are inconsistent with a standard hot-spot rejuvenation model [17], including a 250-1000 m shallow depth anomaly covering the majority of French Polynesia, corresponding to a negative geoid anomaly [18]; elastic thicknesses beneath seamounts and islands typical of much younger lithosphere [19]; high spreading rates [20]; and a disproportionately large number of hot-spot volcanic chains.

The superswell is defined by a regional depth anomaly distribution [17]; based on bathymetric data acquired from the $5^{\prime}$ digital SYNBAPS bathymetry
[21] averaged to $0.25^{\circ}$ and corrected for the variations of sound speed in water, sediment loading and seafloor age, using the standard thermal-plate model [9]. The superswell hypothesis relies heavily on recognizing a depth anomaly which has a magnitude and spatial distribution inconsistent with the simple superposition of anomalies attributed to the individual hot-spots identified in the region $[17,18]$. Since the anomaly extends well eastward of the hot-spot tracks region, to young lithosphere west of the southern East Pacific Rise (SEPR), McNutt and Fischer [17] proposed that the asymptotic lithospheric thickness in this area is less than normal $(75 \mathrm{~km})$ and the asthenosphere is hotter than normal $\left(1385^{\circ} \mathrm{C}\right)$. They also noted that the depth anomaly terminates at the Marquesas Fracture Zone (FZ). This abrupt termination indicated that the cause of the anomaly is related to the lithosphere or uppermost mantle, rather than thermal and/or chemical buoyancy from a deep mantle plume. They suggested that the anomaly was related to small-scale convective instabilities in the low-viscosity zone at the base of the lithosphere.

While the superswell model may effectively explain additional anomalous observations, such as low mantle seismic velocities and low elastic-plate thicknesses (note contrary elastic thickness observations $[22,23])$, the first-order conclusion is that there is a regional depth anomaly which is independent of the effects of overlapping hot-spots, thickened crust and sedimentary aprons. This hypothesis is critically dependent upon the quality of the bathymetric data acquired over the young seafloor just east of the hot-spot tracks (Fig. 1); first, because the observation of anomalously shallow depths in this area is largely responsible for the long-wavelength (presumably age-dependent) anomaly; and, second, because the anomaly attributed to the difference between a 125 $\mathrm{km}$ thick plate with a $1350^{\circ} \mathrm{C}$ basal isotherm and a $75 \mathrm{~km}$ thick plate with a $1385^{\circ} \mathrm{C}$ basal isotherm [17] would be very small in this region (less than $300 \mathrm{~m}$ for $40 \mathrm{Ma}$ lithosphere). We show here that ETOPO-5 (which is equivalent to SYNBAPS in ocean areas) is inappropriate for estimating depth anomaly patterns at intermediate wavelengths (hundreds of kilometers) in this poorly surveyed region.

The depth-age relationship on the flanks of the SEPR adjacent to the superswell has been investigated using single beam acoustic data [24]. Depth 
soundings from a suite of near-parallel tracks were stacked (arithmetic mean) after matching isochrons and removing sections of bathymetry that were obviously perturbed by seamounts and ridges. For young seafloor $(0-5 \mathrm{Ma})$ between $9^{\circ} \mathrm{S}$ and $22^{\circ} \mathrm{S}$, Cochran [24] finds a pronounced asymmetry in seafloor slope; the western flank has a seafloor slope of $200-225 \mathrm{~m}$ $\mathrm{Myr}^{-1 / 2}$ and the eastern flank, 350-400 $\mathrm{m} \mathrm{Myr}^{-1 / 2}$ (since there are alternative processes to thermal subsidence which affect the final observed seafloor slope, 'subsidence rate' is strictly defined as the process of seafloor deepening with age, while 'seafloor slope' refers to the observed change in depth with age for adjacent seafloor sections). By an age of $5 \mathrm{Ma}$ the west flank is $300 \mathrm{~m}$ shallower than the east flank. The youngest seafloor west of the SEPR is already characterized by unusual depth-age behavior even near the SEPR axis. Since the rise axis in that area is anomalously deep to start with (2625-2872 $\mathrm{m}$ ), there is no anomalously shallow seafloor on the western flank. The main anomaly is the very high seafloor slope and deep seafloor on the eastern flank [24].

Proper assessment of the westward extension of the region of low seafloor slope is limited by the paucity of data and by an abundance of large seamounts. Seamounts on normal seafloor generally account for about $0.5 \%$ of the normal crustal volume [25] (i.e., $30 \mathrm{~m}$ of extra crustal thickness). However, on the west flank of the SEPR $\left(6^{\circ} \mathrm{S}-23^{\circ} \mathrm{S}\right)$ and in the Tiki Basin $\left(15^{\circ} \mathrm{S}-21^{\circ} \mathrm{S}\right)$ seamount population density is much greater than normal [26,27], especially near the SEPR between $15^{\circ} \mathrm{S}$ and $19^{\circ} \mathrm{S}$ on $0-6 \mathrm{Ma}$ crust, where the volume of volcanoes and flows is up to $120 \mathrm{~m}$ of extra average crustal thickness [28]. On a pair of recent cruises (GLOR3B-04MV) we found that the unusually high seamount abundance also extends much further to the west-northwest, along the Pukapuka chain [29]. Major ridges along this chain consist of individual segments that are $40 \mathrm{~km}$ long, $<10 \mathrm{~km}$ wide and range in peak amplitude from $800 \mathrm{~m}$ to over $4000 \mathrm{~m}$. Four of the seven tracks used by Cochran [24] west of $128^{\circ} \mathrm{W}$, in the area where a $500 \mathrm{~m}$ shallowing is inferred, cross these major ridges, resulting in substantial shallowing bias.

In addition to the problems with the single-beam coverage in this area, gridded bathymetry, which is based largely on these few tracks, will also have the bias caused by the volcanic ridges as well as the many other problems associated with the ETOPO-5 dataset [30]. The purpose of this paper is to apply a mode estimation technique (histogram) to multibeam data (Fig. 1) in order to establish the correct seafloor depth between the SEPR and the Tuamotus plateau. These results are compared with similarly obtained, depth-age profiles on the conjugate section of the Nazca Plate and on the Pacific Plate north of the Marquesas FZ and are also compared with the global variation in seafloor slope [31]. Deviations from expected subsidence behavior are used to place reliable constraints upon the amplitude and regional extent of the superswell depth.

\section{Data}

\subsection{Bathymerry}

Multibeam data were culled from 8 survey legs (GLOR3BMV, GLOR04MV, WEST01MV, WEST04MV, ARIA02WT, RC2608, TUNE02WT and PPTU03WT). The first 7 comprise the majority of the swath coverage between the Marquesas and Austral FZ's (Fig. 1). GLOR3BMV and GLOR04MV bathymetry are from our recent survey of the Pukapuka Ridge System. Legs designated WT and RC use an older generation of SeaBeam, having 16 beams spanning a swath $2 / 3$ times the ocean depth and legs designated MV use a newer SeaBeam 2000 system, with 121 beams mapping a much wider swath of 3.4 times the ocean depth at $\sim 100 \mathrm{~m}$ resolution for normal ocean depths. Travel times for pings are converted to bathymetry using a local sound velocity profile measured with expendable bathothermographs (XBT). Bathymetric data are cleaned and merged with continuous-time Global Positioning System satellite navigation and processed using MB-system software [32]. Since interference by pinger bursts during periods of dredging operation result in erroneous bathymetry, all records for which ship speed is less than $3 \mathrm{~km} / \mathrm{h}$ were edited from the day files.

The speed-filtered ping record files were grouped into six independent datasets (Fig. 2) and gridded at $200 \mathrm{~m}$ cell size in order to even out the data density while preserving the characteristic high resolution of multibeam data; gaps were not filled with interpo- 
lated values. The first $\mathrm{E}-\mathrm{W}$ dataset consists mainly of GLOR3BMV-GLOR04MV cruise multibeam data; it is supplemented by RC2608 and TUNE02WT in the immediate vicinity of the cruise track (within approximately $70 \mathrm{~km}$ ). The second E-W dataset consists of only the WESTOIMV transit data and, thus, it does not follow any particular topographic features. The third and fifth $E-W$ datasets consist of WEST04MV data, which samples both the west (third) and east (fifth; not shown) flanks of the SEPR, along a line of latitude $16^{\circ} 45^{\prime} \mathrm{S}$. The fourth $\mathrm{E}-\mathrm{W}$ dataset consists of the ARIA02WT cruise data; it is used to constrain seafloor depth just north of the Austral FZ. The sixth E-W dataset, PPTU03WT (Fig. 1), is used to constrain seafloor depth north of the Marquesas FZ, the reported boundary of the superswell [17]. All together, the first 4 datasets cover the eastern flank of the superswell and thus provide a regional view of the depth. The depth anomaly in this area, based on ETOPO- 5 data, ranges from $250 \mathrm{~m}$ at $125^{\circ} \mathrm{W}$ to $400-600 \mathrm{~m}$ at $135^{\circ} \mathrm{W}$ (contours in fig. 2 from McNutt and Judge [18]). The last two datasets constrain seafloor depth on the nearby non-superswell conjugate Nazca Plate and north of the Marquesas FZ on the Pacific Plate.

\subsection{Magnetics}

Ages were determined along the multibeam bathymetry datasets using a suite of selected mag-

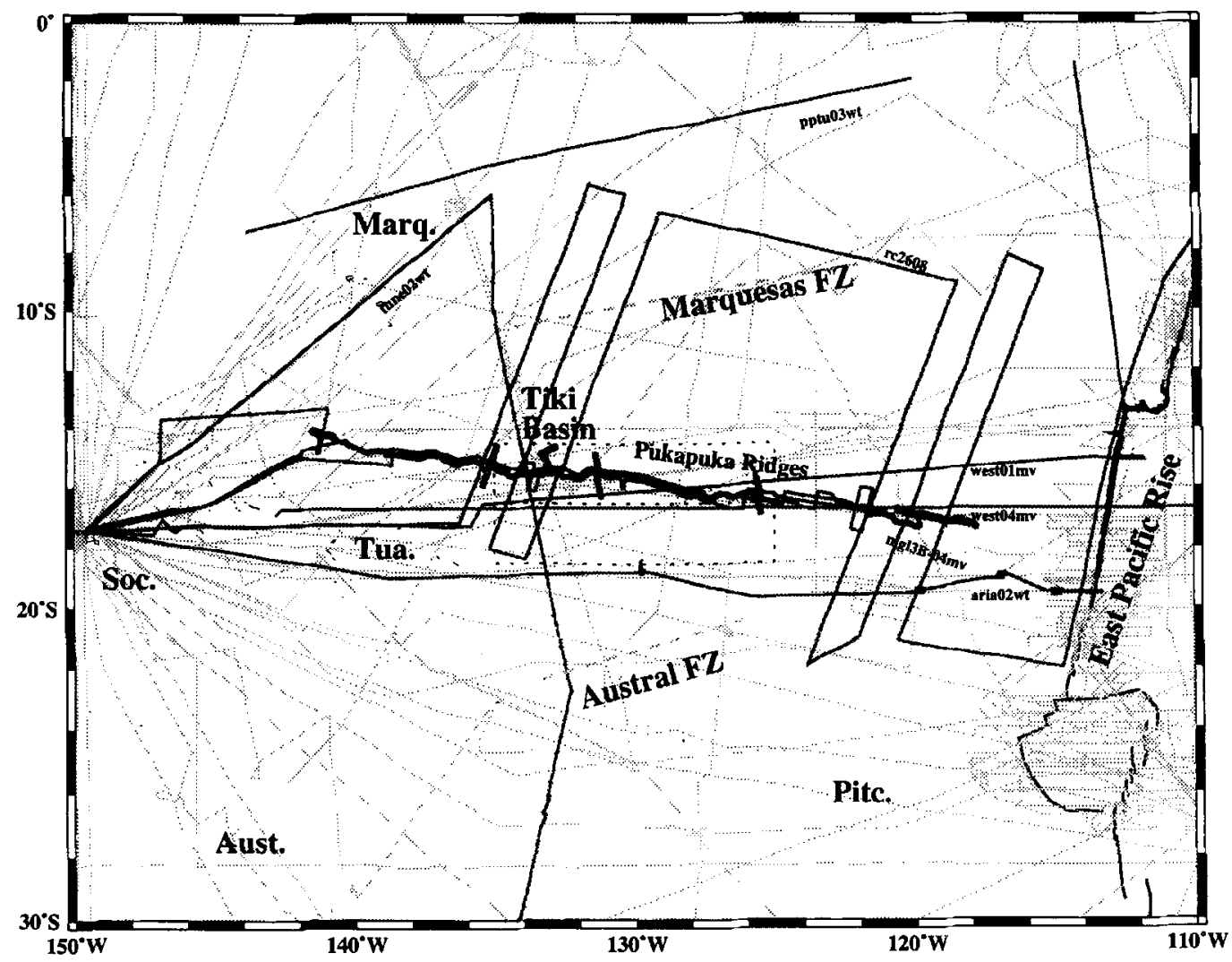

Fig. 1. Mercator map of the northeastern section of the South Pacific Superswell $[17,18]$ showing multibeam (thick lines) and single beam (thin lines) surveys. Also shown are portions of the East Pacific Rise (solid) in the east, the Marquesas and Austral Fracture Zones, the Tiki Basin and the centers of major local hot-spot swells (Austral, Marquesas, Pitcaim, Society and Tuamotus). The dashed rectangles delineate boundaries of data used for a comparison of single-beam bathymetry and ETOPO-5 (see below). Note that, while there appears to be substantial single-beam coverage of seafloor bathymetry south of the Marquesas Fracture Zone on proposed 'Superswell' seafloor, much of the region is characterized by unusually pervasive volcanism, which may bias seafloor depth estimation (sec below). 
netic anomaly profiles in the region (except for datasets 5 and 6, see below). Magnetic profiles from legs amph1, aria2, c1306, cn011, gecsj, gecsk, ggl34, gg192, kk717, kk723, v1905 and vlcn8 (not shown) were acquired from the Lamont-Doherty Earth Observatory on-line geophysical database [30] and legs glor $3 \mathrm{~b}$, glor 04 and west 04 were acquired from the SIO-GDC. Magnetic anomaly picks (Fig. 2) along the multibeam tracks were mostly made from the individual surveys; in some portions of the survey ambiguous magnetic information was supplemented by interpolation between nearby magnetic profiles.

Anomaly picks were straightforward for datasets 1, 2, 3 and 4 (on the Pacific Plate south of the Marquesas FZ) over the majority of the track lengths. From the ridge crest to anomaly $5 \mathrm{~A}(11.8 \mathrm{Ma}$ in a revised timescale [33]) the isochrons correspond closely to previous anomaly picks $[24,33,34]$. Complicated seafloor spreading history $[24,34,35]$ in the early-middle Miocene (12-20 Ma) obscures much of the anomaly pattern between anomaly $5 \mathrm{~A}$ and anomaly $7\left(\sim 122^{\circ} \mathrm{W}-128^{\circ} \mathrm{W}\right)$. However, the magnetic anomaly pattern recorded from the recent glor $3 \mathrm{~b}$, glor04 and west04 tracks confirms magnetic anomaly picks locally from 5A through 6AA. These picks result in a period of uncharacteristically slow spreading $(\sim 30 \mathrm{~km} / \mathrm{Ma})$ between anomalies 6AA and 7. Nevertheless, only moderate error (a few hundred thousand years, equivalent to a depth error on the order of a few tens of meters) is likely to be introduced by accepting these picks instead of assuming uniform moderate spreading ( $\sim 60 \mathrm{~km} / \mathrm{Ma})$ over this interval. From anomaly 7 to 16 , the magnetic signature is clear; isochron locations based on the magnetic data are clear and correspond closely to previous studies $[29,36]$. Therefore, ages are well constrained over the older section of the survey, where the proposed superswell-related depth anomaly is expected to be greatest.

Anomaly picks on the conjugate section of the



Fig. 2. Mercator map showing $5 \mathrm{E}-\mathrm{W}$ multibeam transect datasets on the west flank of the East Pacific Rise: $1=$ the GLOR3B-04MV; 2 = WEST0IMV; 3 = WEST04MV-west; 4 = ARIA02WT dataset (thick lines). Multibeam data from WEST04MV-east (dataset 5) and PPTU03WT are located east of the SEPR and north of the Marquesas FZ, respectively, and are not shown on the map. Contours correspond to depth anomalies assuming a $125 \mathrm{~km}$ thick lithospheric plate digitized directly from fig. 2 of McNutt and Judge [18]. Short dashed lines represent isochron locations based on anomaly picks from a suite of local magnetic profiles and age calibration is based on a revised magnetostratigraphic timescale [33]. 
Nazca Plate (for dataset 5) were obtained directly from [36] and Cande [pers. commun., 1995]. Although the magnetic signature is unclear from $91^{\circ} \mathrm{W}-100^{\circ} \mathrm{W}$ (near the Mendana FZ), and we suspect that the track crosses an undocumented fracture zone near $106^{\circ} \mathrm{W}$, the interpolated age trend is nearly
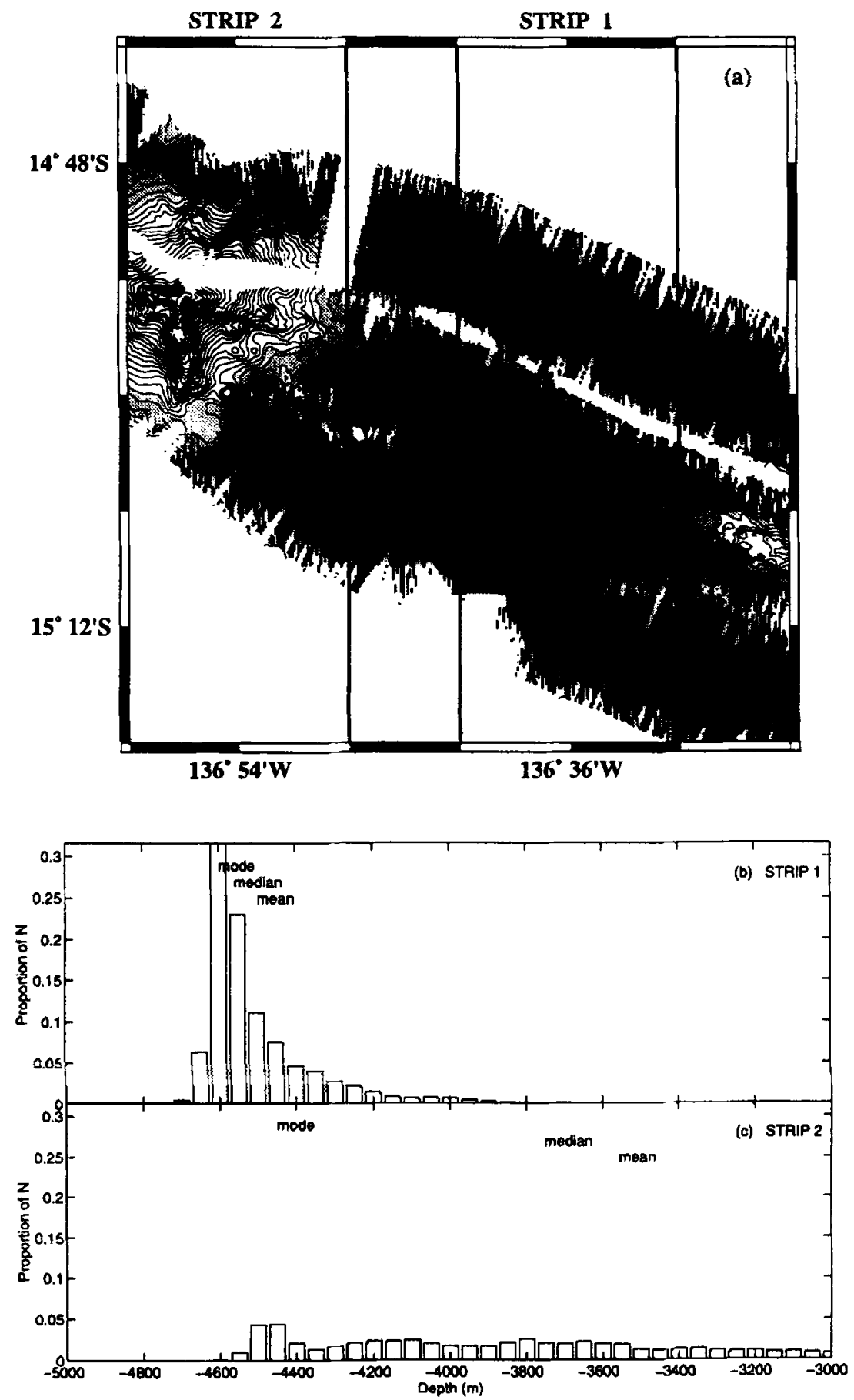
constant from the spreading axis at $118^{\circ} \mathrm{W}$ to $39 \mathrm{Ma}$ at $79^{\circ} \mathrm{W}$, near the Nazca Ridge. A comparison of a digital age database [37] and our aforementioned picks on conjugate sections of the Pacific and Nazca Plates south of $10^{\circ} \mathrm{S}$ reveals an approximate correspondence (within $2 \mathrm{Ma}$ ) over the profile length. Since little new magnetic information is available on the Pacific Plate north of the Marquesas FZ, age determination for dataset 6 (on the Pacific Plate north of the Marquesas FZ) was obtained directly from the digital age database [37].

Magnetic anomaly picks were correlated with a new magnetostratigraphic time scale [33]. The new time scale contains several significant modifications in the ages attributed to isochrons, mostly due to changes in calibration points. Most importantly, age estimates for the subdivisions of the Paleogene have changed considerably. Ages attributed to anomalies 9-19 may be 2-4 Myr younger than most previous time scales, making depths of 25-35 Ma seafloor appear approximately $50-70 \mathrm{~m}$ shallower. Once ages are established for control points corresponding to the anomaly picks, ages are estimated at other points along each dataset (except for dataset 6, as noted above) by cubic spline interpolation. Errors related to splining are small (a few ten thousand years) in comparison to the timescale variation, because the greatest separation of control points is about $3 \mathrm{Myr}$ (except for dataset 5) and because spreading rate can be expected to remain reasonably constant in between.

\section{Mode estimation}

The standard parametric approach to evaluating distribution density assumes that the data are drawn from a known distribution, such as the normal distribution (Gaussian, with mean $\mu$ and variance $\sigma^{2}$ ). In this case, the mean is used to estimate the most likely value of the data. There are several complicating factors which affect the distribution of seafloor depth, causing it to be poorly fit by a Gaussian or even Poisson distribution function. Thus, the most likely seafloor depth is best estimated using a simple non-parametric approach: the histogram. Although other estimation techniques, such as the naive estimator and the kernel estimator [38], are, perhaps, more precise and mathematically rigorous, the histogram is employed here due to its shorter computation time and ease of interpretation.

We developed an automatic procedure for estimating unperturbed 'true' seafloor depth in areas containing numerous seamounts and ridges, based directly on the flatness of the unperturbed sections and the ruggedness of the disturbed sections, using a binning procedure. Seafloor depth data from the seamounts and ridges will have a low, broad histogram while the data from the flat surrounding seafloor will have a tall, narrow histogram. We assume that the tallest bin corresponds to the 'true' seafloor depth in a given area. The method estimates the 'true' seafloor depth in areas where less than $20 \%$ of the seafloor contains flat bottom values (see below). Estimation sensitivity should, in theory, increase with decreasing section area or bin width, although in practise it is limited by 'real' topographic noise.

\subsection{Means, medians and modes}

An example of the modal method from an area of rugged topography, is shown in Fig. 3a, a section of seafloor from dataset 1 . The section contains an elongated ridge terminating at about $136^{\circ} 34^{\prime} \mathrm{W}$ and a tall seamount centered at $136^{\circ} 57^{\prime} \mathrm{W}$. Fig. $3 \mathrm{~b}$ and $\mathrm{c}$ show $50 \mathrm{~m}$ wide bin histograms of the bathymetry recovered from $0.2^{\circ}$ wide north-south strips, cen-

\footnotetext{
Fig. 3. (a) Shaded contour map of SeaBeam 2000 data acquired during survey legs GLOR3B-04MV (dataset 1 ; between $137^{\circ} 00^{\prime} \mathrm{W}$ and $136^{\circ} 12^{\prime} \mathrm{W}$ ) and gridded with $200 \mathrm{~m}$ grid cell dimensions. Shading ranges from -4900 to $-3500 \mathrm{~m}$ in depth. (b) Histogram of depths in strip 1 of data (between $136^{\circ} 42^{\prime} \mathrm{W}$ and $136^{\circ} 30^{\prime} \mathrm{W}$ ) in $50 \mathrm{~m}$ bins. Note that the bin populations are normalized by the total number of data values and that the displayed bin range is from -5000 to $-3000 \mathrm{~m}$. The small difference between the mean, median and mode estimators suggests that the mean and median are adequate for nearly flat seafloor. (c) Histogram of depths in strip 2 of data (between $137^{\circ} 00^{\prime} \mathrm{W}$ and $136^{\circ} 48^{\prime} \mathrm{W}$ ) in $50 \mathrm{~m}$ bins. The large difference between the mean, median and mode estimators suggests that the mean and median are biased estimators of seafloor depth over highly perturbed terrain.
} 
tered at $136^{\circ} 36^{\prime} \mathrm{W}$ and $136^{\circ} 54^{\prime} \mathrm{W}$, respectively. Strip 1 is representative of mostly flat seafloor, with perturbations due to the toe of the ridge to the east, a small seamount in the south and the downward slope of the large seamount in the west. The distribution of depths at this location (Fig. 3b) has a small standard deviation $(155 \mathrm{~m})$ and is only slightly skewed to shallow values, so that the mean $(-4499 \mathrm{~m})$, the median $(-4559 \mathrm{~m})$ and the mode $(-4600 \mathrm{~m})$ are fairly close. In this case the median is an adequate estimator of the 'true' seafloor depth, although it may be consistently biased to shallow values. Depths along strip 2 , only $30 \mathrm{~km}$ to the west, have a completely different histogram, reflecting the presence of a large ( $3 \mathrm{~km}$ high) seamount (Fig. $3 \mathrm{c}$ ). The histogram of depths shows a multimodal distribution which is extremely long-tailed. The standard deviation is large $(820 \mathrm{~m})$ because the seamount is tall and highly sloped. The seafloor depths estimated by the parametric mean $(-3557 \mathrm{~m})$ and median $(-3754$ m) are very different from that obtained by the non-parametric mode $(-4450 \mathrm{~m})$, which approximately corresponds to the intuitive expectation for the unperturbed seafloor depth and is also close to the value of the seafloor depth in strip 1. In this example, the 'true' seafloor depth was estimated even though flat seafloor (in the southeast corner of strip 2) covered less than $10 \%$ of the swath.

\subsection{Bin resolution and dataset size}

The automated selection of the modal bin depends on two adjustable parameters: the depth resolution used for the bins and the size of the area included in the histogram. Our goal is to estimate a representative depth for the seafloor which is suitable for depth-age regression, to retain intermediate wavelength depth-age variation. As shown in Fig. 3b, the modal estimation of seafloor depth is particularly effective when the seafloor is mostly flat, but seafloor generated at faster spreading ridges contains abyssal hills, which consist of elongate, ridge-parallel topography at $1-10 \mathrm{~km}$ spacing and $\sim 100 \mathrm{~m}$ of relief. Abyssal hills are observed along the multibeam surveys with an amplitude of $50-200 \mathrm{~m}$ and a wavelength of one to tens of kilometers. To minimize errors associated with abyssal hill-related multimodes, the bin width in this area should be greater than or equal to the typical abyssal hill relief. Furthermore, variable sedimentary deposition, on the order of a few tens of meters, throughout the survey areas is likely to limit further depth estimation resolution. Based on trial and error, a $50 \mathrm{~m}$ bin is used, although some fine tuning of the result was obtained by calculating the mean of all data within $100 \mathrm{~m}$ of the modal bin.

A second related issue regarding modal depth estimation is the size of the area to include when constructing the histogram. For a given bin width, as the survey area becomes more populated with constructional features, it becomes increasingly likely that the bin which represents the seafloor depth will be mislocated. Once again, trial and error suggests that, for $0.2^{\circ}$ wide datasets, $98 \%$ of the estimates corresponded to the intuitive expectation of the value (the remaining $2 \%$ estimate an anomalously tall bin from the tail), while that percentage decreased dramatically as window size is decreased. This dataset windowing size is optimal for dataset 1 , which focused on the Pukapuka Ridges, as well the other datasets, which were obtained from 'average' seafloor, because of its relatively increased coverage (three swaths of wider SeaBeam2000). Intra-window subsidence should not substantially bias the depth estimation since, for an average spreading rate of 70 $\mathrm{km} \mathrm{Myr}^{-1}$ and a subsidence rate of $350 \mathrm{~m} \mathrm{Myr}^{-1 / 2}$, the subsidence-related change in seafloor depth should only be of the order of tens of meters over the 5-36 Ma survey age range. However, estimates may reflect roughness attributed to abyssal hill relief at a wavelength approximately equal to the window size. While the short wavelength (tens of kilometers) roughness inherent in this windowing scheme will be useful for considering the respective amplitude of abyssal hill fabric and surficial volcanics as they affect the various seafloor depth estimators, it is not likely to bias the overall depth-age regression trends significantly.

\section{Results}

The seafloor depth estimates along dataset 1 , in the vicinity of the Pukapuka Ridge System, illustrate the advantages of non-parametric techniques in de- 
termining an unbiased seafloor depth value. Modeestimated values for the $0.2^{\circ}$ wide window are almost universally deeper than values estimated by the mean and median (Fig. 4). Over the interval from $117^{\circ} \mathrm{W}$ to $137^{\circ} \mathrm{W}$, the average modal depth $(-3922$ $\mathrm{m})$ is $81 \mathrm{~m}$ deeper than the median value and $165 \mathrm{~m}$ deeper than the mean. The sharp peaks observed in the mean and median estimators (Fig. 4) correspond to a large topographic feature within the window. Conversely, the ruggedness of the mode estimation is nearly uncorrelated, at short wavelength, with the mean and median variation and with the location of ridges and seamount clusters and is almost entirely attributed to abyssal hill relief. While the short-wavelength variation in the mode is generally less than $100 \mathrm{~m}$, the mean frequently varies by several hundred meters, due to the great volume of perturbing volcanics. Areas in which the mode-mean difference is consistently large, from $117^{\circ} \mathrm{W}$ to $121^{\circ} \mathrm{W}$, from $125^{\circ} \mathrm{W}$ to $127^{\circ} \mathrm{W}$, from $129^{\circ} \mathrm{W}$ to $130^{\circ} \mathrm{W}$, and from $134^{\circ} \mathrm{W}$ to $139^{\circ} \mathrm{W}$, correspond directly to areas which are observed to contain the largest concentration of prominent volcanic features [29].

Since the mode corresponds to the unperturbed seafloor depth, the integrated volume of volcanic material can roughly be calculated by subtracting the volume below the mode, attributed to abyssal hill topography, from the volume above the mode. For dataset 1 the average columnar height is $150 \mathrm{~m}$, roughly equivalent to about $2.5 \%$ of the volume of the crust. This large value is not surprising, since the primary goal of GLOR3B-04MV was to survey a set of continuous prominent ridges.

The other seafloor depth estimation datasets $(2-5$; not shown) do not purposely encounter high concentrations of volcanoes so that the mean, median and mode values are very close. The selected mode values for datasets 2 and 3 are very close to the dataset 1 values for nearby locations, confirming the improved depth estimation availed by the mode estimator over rugged terrain. Most importantly, these results suggest that, where there is sufficient swath coverage, the mode estimation technique can provide a more accurate (deeper) and reliable depth value than the mean and median in areas of robust volcanism, as in dataset 1 , and an equally accurate and reliable depth value in areas of flat seafloor. The amount of extrusive volcanic material averaged over the length of these surveys is equivalent to a marginal fraction of crustal volume $(<0.5 \%)$. Accurate quantitative estimation of the small volume of the diffuse distribution of volcanics for these surveys is likely to be highly sensitive to the distribution of abyssal hill scarps relative to the dataset cutoff locations and the area of non-volcanics sampled. Thus, an automatic procedure is only possible by elimination of nonvolcanic data points and finer-scale seafloor bottom determination [28].

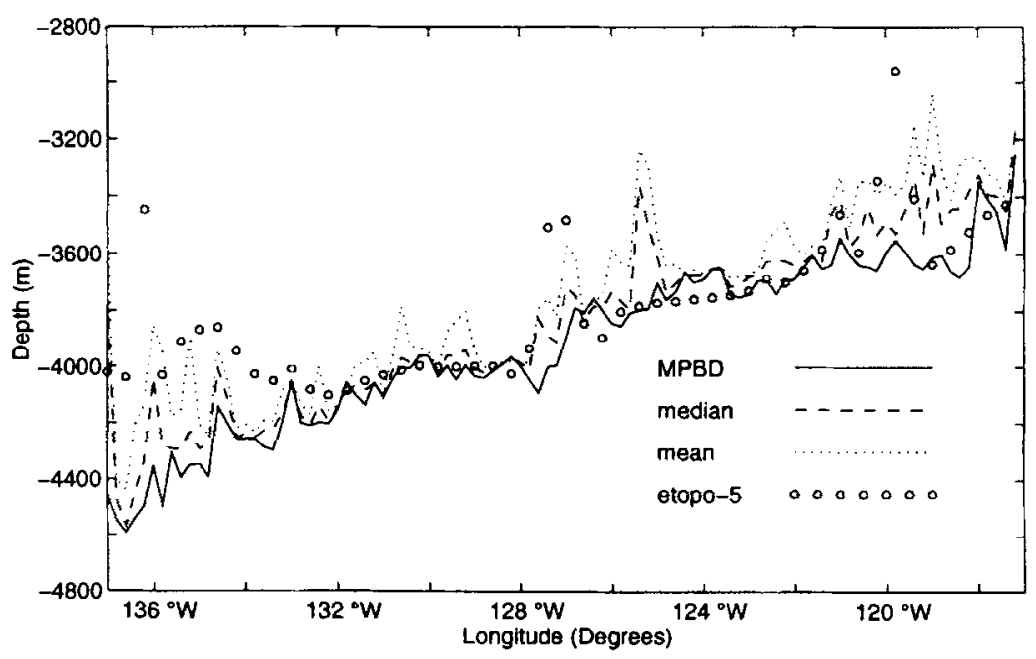

Fig. 4. Estimated depths (mode, median and mean) and ETOPO-5 depths for $0.2^{\circ}$ wide (E-W) strips of the combined GLOR3B-04MV dataset (1) near the Pukapuka Ridges (see Fig. 1). 


\section{Discussion}

\subsection{Modal depth versus age}

The modal depth estimates can be compared with the expected depth based on the standard plate cooling model [9] (PSM; Fig. 5a-f). Fig. 5a-d shows the variation of modal and the ETOPO-5 depths (both corrected for a representative, uniform $50 \mathrm{~m}$ thick sediment layer), with age on the EPR west flank south of the Marquesas FZ (datasets 1-4), in comparison with the PSM predicted depth. Seafloor proximate to the EPR axis (datasets 3 and 4 ) is deeper than the prediction of the standard model [9]. Although older seafloor (0-38 Ma) generally subsides monotonically nearly as fast as the rate predicted by the standard model; a shallowing depth anomaly gradually increases from $0 \mathrm{~m}$, near $10 \mathrm{Ma}$, to over $200 \mathrm{~m}$, near $22 \mathrm{Ma}$, in a region characterized by rough bathymetry and complexities in the magnetic anomaly pattern, which have been associated with the Miocene reorganization of the spreading center $[24,34,35,39]$. Importantly, the depth anomaly diminishes to zero just prior to rising sharply at the toe of the Tuamotus Plateau.

The GLOR3B-04MV survey (dataset 1) obtained multibeam bathymetry in close proximity to a set of volcanic ridges, which are confined to the trough of a set of gravity lineations [29]. The dataset 2 and 3 modal values corroborate the main depth-age regression features of dataset 1 (Fig. $5 b$ and $c$ ); more than $95 \%$ of the synchronous estimates fall within $50 \mathrm{~m}$ bounds for the three datasets. Thus, the depth-age trends observed in the Pukapuka Ridge survey data are not the result of a deepening bias by a bathymetric trough or as a flexural response to the load of volcanic ridges. Dataset 4 modal values, $\sim 200 \mathrm{~km}$ to the south, show a similar depth-age relationship.

Taken together, these depth-age profiles demonstrate that the depth anomaly proposed for the young section of the superswell region is of the order of $200 \mathrm{~m}$ or less. The improved depth estimation method of multibeam soundings and the shift in age attributed to the recently revised magnetostratigraphic calibration of Cande and Kent [33] are the most likely explanations for the failure of the present study to verify large depth anomalies $(>500 \mathrm{~m}$ ) $[17,18,24]$.

\subsection{Gridded depth versus age}

The existence of an age-dependent anomaly over the superswell [17] is based on the sediment-corrected, gridded bathymetry (McNutt and Fischer [17], fig. 3). Our depth-age results (Fig. 5a-c), approximately match the gridded bathymetry up to $30 \mathrm{Ma}$ but at older ages (30-37 Ma) our depth estimates are progressively deeper, by $200-400 \mathrm{~m}$, where we surveyed a sequence of large seamounts and guyots [29]. From 28 to $37 \mathrm{Ma}$ the gridded bathymetry appears to reflect an affinity for the $-4000 \mathrm{~m}$ contour (before $50 \mathrm{~m}$ sediment correction), suggesting that the overly shallow ETOPO-5 bathymetry is the result of splining sparse seamount-derived con-
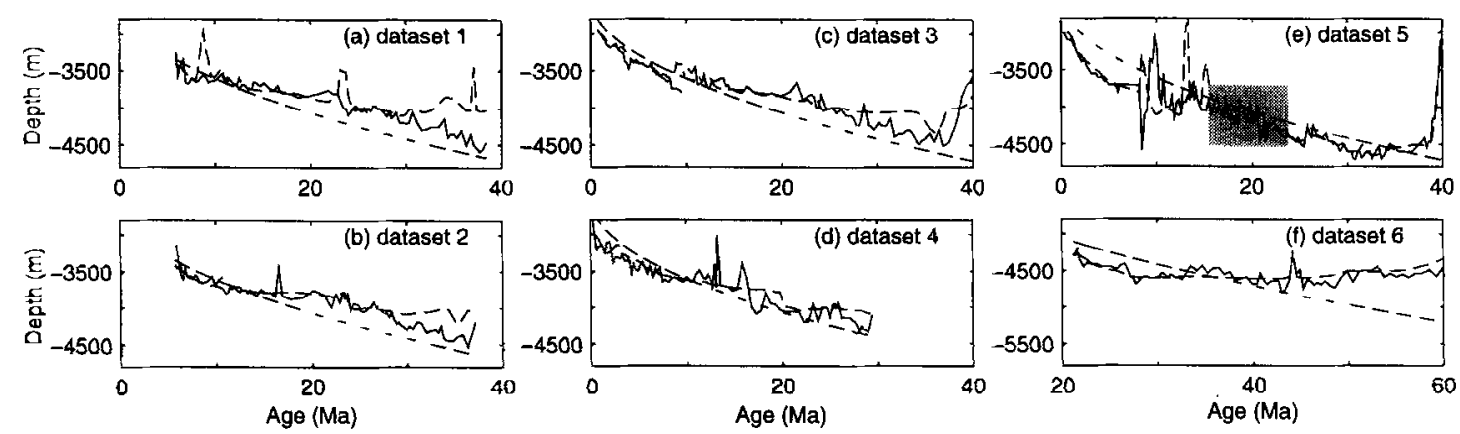

Fig. 5. Mode estimated (solid) and ETOPO-5 (short dash) depths for $0.2^{\circ}$ wide (E-W) strips obtained from six datasets used in this study plotted as a function of age (see text), corresponding to datasets 1-6. Datasets 1-4 are on the Pacific Plate south of the Marquesas FZ, dataset 6 is north of the Marquesas and dataset 5 is on the conjugate section of the Nazca Plate. The plate-model depth is shown for comparison (long dash). The area where there are no clear magnetic anomaly picks is shaded in (e). Note the age range difference in (f). 
tour maps, which are unrepresentative of the ambient seafloor depth.

The tendency for the various digital bathymetry databases to show bulges and excessive flatness, particularly at integral multiples of the $500 \mathrm{~m}$ contour interval, has been noted [30]. It has been attributed to the fact that ship soundings were not directly used in gridding - they were prepared by digitizing contours from GEBCO charts and by gridding the coordinates of these contours. Fig. 6 shows a comparison of ETOPO-5 (which includes SYNBAPS) with all ship soundings obtained from the SIO-GMT database [30] within two adjacent and parallel $2^{\circ}$ wide E-W corridors from $125^{\circ} \mathrm{W}$ to $135^{\circ} \mathrm{W}$ (see Fig. 1). The gridded bathymetry and ship soundings show an increasingly shallow anomaly in the gridded database from $125^{\circ} \mathrm{W}$ to $130^{\circ} \mathrm{W}$. However, for the western portion of the area $\left(130^{\circ} \mathrm{W}-\right.$ $133^{\circ} \mathrm{W}$ ), the gridded data are increasingly shallow, by up to $300 \mathrm{~m}$, in comparison to sounding data. The smooth, age-related anomaly observed over this young section of the proposed superswell $(>500 \mathrm{~m}$ ) is mostly the product of flatness in a gridded bathymetry database which does not adequately represent the seafloor depth. Whatever anomaly exists $(\sim 250 \mathrm{~m})$, tapers off to near zero just prior to encroaching upon the thickened crust and sedimentary aprons of the Tuamotus plateau [40].

\subsection{Anomalous subsidence and the 'superswell'}

A depth anomaly of the order of $100 \mathrm{~m}$ is within the global range of variation of seafloor slope [31]. Furthermore, the depth anomaly attributed to the spreading segment on the Pacific Plate between the Austral and the Marquesas FZs is similar in magnitude to those observed on the Pacific Plate north of the Marquesas FZ (Fig. 5f) and on the conjugate section on the Nazca Plate (Fig. 5e), so that the depth anomaly is not bounded by tectonic elements such as fracture zones and spreading axes. The depth-age trend on the west flank of the SEPR is similar to the conjugate section on the east flank of the SEPR. In particular, from 13 to $35 \mathrm{Ma}$, the Nazca Plate appears to subside roughly at the same rate as the corresponding 'superswell' section on the Pacific Plate but is deeper by approximately $250 \mathrm{~m}$. Note that observations of the general trend of depth with age on the east flank of the SEPR are not susceptible to possible inaccurate age assignment from $100^{\circ} \mathrm{W}$ to $92^{\circ} \mathrm{W}$, since the expected error based on the offset across the Mendana FZ [37] ( 1 Myr $)$

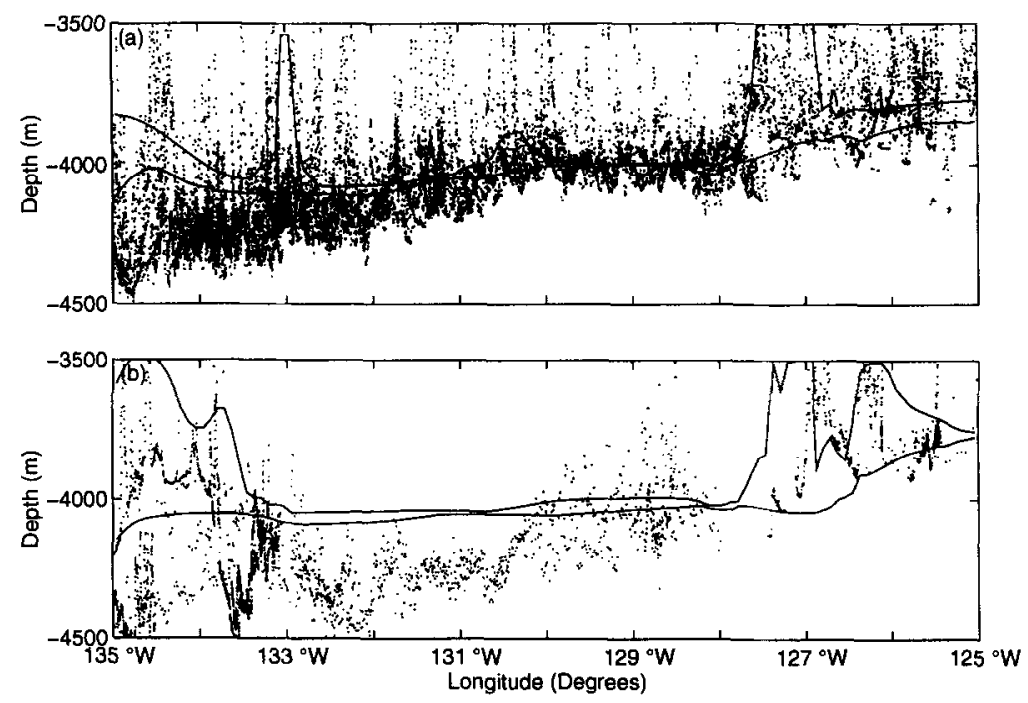

Fig. 6. Original single-beam ship sounding depths (points) in comparison with the upper and lower boundary (solid lines) for all ETOPO-5 gridded depths for two adjacent, parallel, E-W strips from $125^{\circ} \mathrm{W}$ to $135^{\circ} \mathrm{W}$ (shown in Fig. 1). (a) $14.5^{\circ} \mathrm{S}-16.5^{\circ} \mathrm{S}$. (b) $16.5^{\circ} \mathrm{S}-18.5^{\circ} \mathrm{S}$. ETOPO-5 adequately represents seafloor depths from $125^{\circ} \mathrm{W}$ to $130^{\circ} \mathrm{W}$ but further west the gridded bathymetry underestimates depth by several hundred meters. 
is equivalent to an error of $50 \mathrm{~m}$ in relation to age. The large drop in the depth anomaly across the Marquesas FZ suggested that the Marquesas FZ presents a natural boundary between anomalously thin and hot superswell lithosphere, to the south, and normal lithosphere, to the north $[17,18]$. However, the depth estimates in the present study fail to reproduce this comparative constant shallowing offset for the southern segment. While the northern estimates (Fig. 5f) from $125^{\circ} \mathrm{W}$ to $136^{\circ} \mathrm{W}$ (29-52 Ma) show a depth anomaly that increases from $-200 \mathrm{~m}$ to 600 $\mathrm{m}$ (extremely low seafloor slopes), the geographically corresponding southern estimates (16-37 Ma) show a near-constant shallow anomaly of approximately $100 \mathrm{~m}$. For the period $29-37 \mathrm{Ma}$, the difference in depth is approximately $100-250 \mathrm{~m}$, less than the present offset across fracture zones at the EPR axis.

Most importantly, the new depth estimates fail to establish an anomalous, age-related, long wavelength trend in the shallowing of the data, since the seafloor of 13-37 Ma is very nearly as deep as the plate-model prediction. On the contrary, similar to Cochran's results [24], the anomalous ridge flank subsidence extends throughout the entire region younger than the middle Miocene ridge reorientation $(\sim 24 \mathrm{Ma})$. Interestingly, with the exception of the youngest section, where the seafloor slope is unusually high (over $400 \mathrm{~m} \mathrm{Myr}^{-1 / 2}$ ), a similar pattern is developed on the east flank of the SEPR (with a $300 \mathrm{~m}$ deepening offset; see Fig. 5e), although details of the depth-age correlation on the Nazca Plate are limited by coarse magnetic anomaly identification and the possible presence of an uncharted fracture zone at $106^{\circ} \mathrm{W}$. The greatest difference in subsidence behavior is not in the superswell but is evident in the younger section on the west flank of the SEPR, in the area associated with the development of gravity lineations and with the recent production of pervasive, unusually robust volcanics.

\section{Models}

The west flank of the EPR has recently been the focus of intense research due to observations of abundant volcanism, lineations in the altimetric gravity field and an age-dependent, shallowing depth anomaly. While the our study fails to confirm the long-wavelength 'superswell' depth anomaly, it is

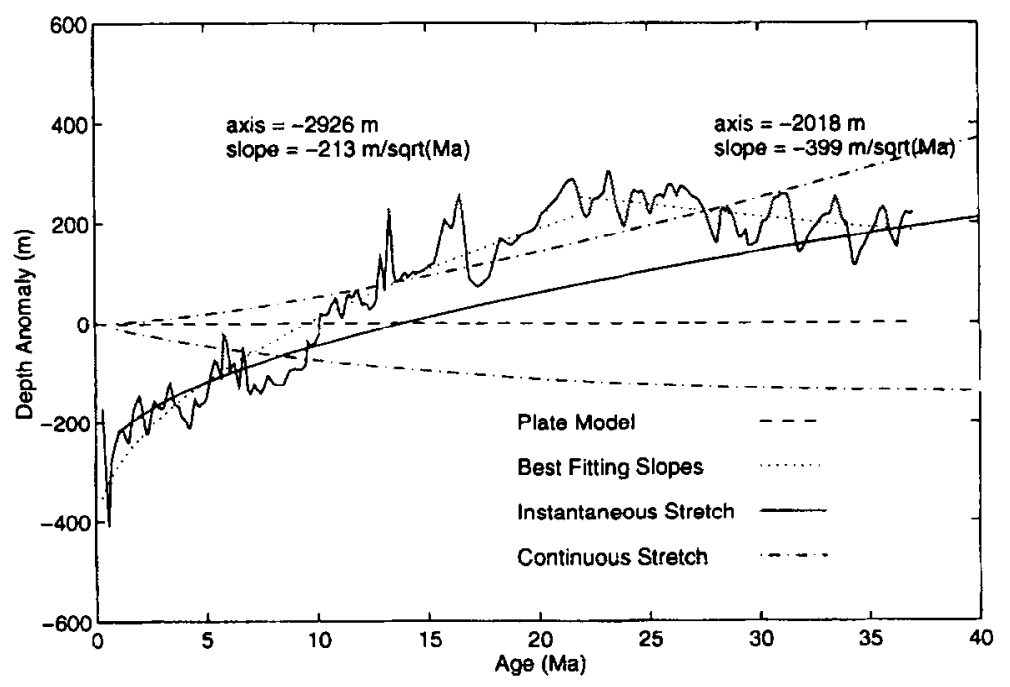

Fig. 7. Depth anomaly as a function of age obtained by subtracting the standard plate model [9] from a mean of modal estimates derived from datasets 1-4 on the west flank of the SEPR, south of the Marquesas FZ (solid line). The horizontal line (dashed) represents no anomaly with respect to the plate model. The best fitting seafloor slope curves are shown for two subintervals (dotted line; see text). An instantaneous stretching episode of $30 \%(\beta=1.3)$, affecting $0-37$ Ma crust, nearly fits the estimated depth curve. Continuous stretching (upper dot-dashed line) over the same interval with a moderate strain rate $\left(\epsilon=3.1 \times 10^{-16} \mathrm{~s}^{-1}\right.$, resulting in $1 \% \mathrm{Myr}^{-1}$ stretching; lower dot-dashed line) barely fits the data, even when the isostatic effect is removed due to continuous crust replacement. 
clear that both flanks of the SEPR have undergone periods of anomalous subsidence, although the magnitude of the corresponding depth anomalies appears to be minor (Fig. 7). The ridge axis is anomalously deep by about $200 \mathrm{~m}$ but by $20 \mathrm{Ma}$ the seafloor is anomalously shallow by about $200 \mathrm{~m}$; at older ages the depth anomaly decays to zero. One can also interpret this depth anomaly in terms of anomalous seafloor slope. Between 0 and $22 \mathrm{Ma}$ the slope is anomalously low, $218 \mathrm{~m} \mathrm{Myr}^{-1 / 2}$, while between 22 and $37 \mathrm{Ma}$ the slope is anomalously high, $399 \mathrm{~m}$ $\mathrm{Myr}^{-1 / 2}$ (Fig. 7). Next, we investigate several possible mechanisms for the depth anomaly on the west flank of the EPR. The models considered are: mantle plume; small scale convection; stretching (instantaneous and continuous); and, finally, variations in crustal thickness (on-ridge and off-ridge). When discussing each model we will also consider constraints from the other geophysical anomalies in the area, such as gravity rolls and low elastic thickness.

\subsection{Mantle plume}

Mantle plumes have traditionally explained a range of observations associated with midplate swells, such as age-progressive linear seamount chains (hot-spot) and a depth anomaly which can exceed $2 \mathrm{~km}$ in amplitude and have a wavelength of $1000-2000 \mathrm{~km}[13,14]$. The depth anomaly distribution on 7-37 Ma Pacific Plate seafloor resembles, in planform, a subtle midplate swell $(\sim 300 \mathrm{~m}$ tall). However, the closest hot-spots, Marquesas and Pitcaim, are too distant to be associated with this plume. The recently charted Pukapuka chain lies in the center of this depth anomaly but the age progression of dredged samples along the Pukapuka chain [29] is not consistent with published absolute plate motion poles attributed to the mini-hot-spot model [41] and the youngest volcanoes are in an areas of zero depth anomaly. While the volcanic expression of a mantle plume is apparently lacking in the area, perhaps a broad, weak plume with a moderate temperature anomaly and dynamic support is maintaining the swell [42], or perhaps flow from more distant plumes is channeled toward the ridge beneath the thinner lithospheric segment south of the Marquesas FZ [43]; this would also provide thermal buoyancy for the swell.

\subsection{Small-scale convection}

Small-scale convection in low-viscosity asthenosphere [8] has been proposed to explain lineations in the gravity field aligned roughly parallel to the recent absolute plate motion direction [44] on the west flank of the SEPR and the anomalously low seafloor slope there $[17,45]$. The original model includes the thermal interaction of the lithospheric thermal lid with a convective, variable low-viscosity boundary layer below, which supplies advective heat [45]. Convection begins at a model age younger than 5 $\mathrm{Ma}$, effectively thinning the thermal lithosphere; causing a progressive shallowing of the seafloor $(\sim 150 \mathrm{~m}$ from 10 to $20 \mathrm{Ma}$ ) with respect to the standard depth-age model. While the heat delivery of small-scale convection may be sufficient to explain the growing depth anomaly, it does not explain the reduction in the depth anomaly on older seafloor in an area where the gravity rolls are strong. Moreover, more than $90 \%$ of the volcanic volume attributed to the Pukapuka Ridges is confined to a trough of the lineations, even though the convective pattern predicts a downgoing flow there. Nevertheless, it is difficult to falsify a small-scale convection model because it is dependent on a variety of poorly constrained parameters [46].

\subsection{Lithospheric stretching}

Lithospheric stretching has been proposed to explain the formation of the Pukapuka Ridges as well as the formation of the gravity lineations by boudinage [29]. Stretching has two effects on seafloor depth anomaly: crustal stretching/thinning increases with depth while lithospheric stretching/thinning decreases with depth, causing a swell. Stretching could occur as a single event or continuously with time. For instantaneous stretching of a cooling half-space, the depth $\Delta \mathrm{d}(t)$ anomaly is given by:

$$
\begin{aligned}
\Delta \mathrm{d}(t)= & -\left(1-\frac{1}{\beta}\right)\left[z_{c} \frac{\left(\rho_{c}-\rho_{m}\right)}{\left(\rho_{m}-\rho_{w}\right)}\right. \\
& \left.-\frac{2 \alpha \rho_{m} T_{m}(\kappa t / \pi)^{1 / 2}}{\left(\rho_{m}-\rho_{w}\right)}\right]
\end{aligned}
$$

where: $t$ is the age of the lithosphere; $\beta$ is the 
stretching coefficient $[6] ; z_{c}(6000 \mathrm{~m})$ is the unstretched crustal thickness; $\rho_{c}\left(2800 \mathrm{~kg} \mathrm{~m}^{-3}\right)$ is the crustal density; $\rho_{m}\left(3300 \mathrm{~kg} \mathrm{~m}^{-3}\right)$ is the mantle density; $\rho_{w}\left(1000 \mathrm{~kg} \mathrm{~m}^{-3}\right)$ is the seawater density; $\alpha\left(3 \times 10^{-5}{ }^{0} \mathrm{~K}^{-1}\right)$ is the volume coefficient of thermal expansion; $\kappa\left(9.75 \times 10^{-7} \mathrm{~m}^{2} \mathrm{~s}^{-1}\right)$ is the thermal diffusivity; and $T_{m}\left(1300^{\circ} \mathrm{K}\right)$ is the asthenospheric temperature. Instantaneous stretching with $\beta=1.3$ (Fig. 7, solid curve) approximately matches the depth anomaly on both young and old lithosphere but underestimates the anomaly in the 10-30 Ma age range. A larger amount of stretching may provide a better fit to the data, but such a large deformation of the lithosphere would be apparent in the spacings of the fracture zones [47]. If the instantaneous extension is accompanied by crustal replacement consisting of extension-generated melt [48] even greater extension may be required.

It is unlikely that stretching of the Pacific plate would occur instantaneously. The other end-member model is a lithosphere that is extending at a constant strain rate $\left(\epsilon=3.1 \times 10^{-16} \mathrm{~s}^{-1}\right.$, resulting in $1 \%$ $\mathrm{Myr}^{-1}$ stretching). In this case the depth anomaly at a seafloor age [49], $t$, is:

$$
\begin{aligned}
\Delta \mathrm{d}(t)= & -\epsilon t z_{\mathrm{c}} \frac{\left(\rho_{m}-\rho_{c}\right)}{\left(\rho_{m}-\rho_{w}\right)}+\frac{2 \alpha \rho_{m} T_{m}}{\left(\rho_{m}-\rho_{w}\right)} \\
& \times\left\{\left(\frac{\kappa}{\pi}\right)^{1 / 2}\left[\left(\frac{1-e^{-2 \epsilon t}}{2 \epsilon}\right)^{1 / 2}-1\right]\right\}
\end{aligned}
$$

Continuous stretching results in a deepening of the lithosphere with respect to the standard model, since the integrated crustal isostatic response (first term) to thinning exceeds the shallowing thermal response (second term). Thus, this model does not adequately fit the depth anomaly data (Fig. 7; lower dot-dashed curve). A modification of this model is to replace crust continuously by intrusive and extrusive volcanism, so it maintains a constant thickness, and the first term in Eq. (2) is zero. In this case, the seafloor shallows with age but provides a poor fit to the data, especially at the spreading ridge (Fig. 7 ; upper dotdashed curve). Instantaneous stretching requires much less total strain than continuous stretching to produce the same depth anomaly because, during the interval of continuous stretching, the thermal pertur- bation has time to decay. Most importantly, in all cases, a great amount of stretching is required to yield significant variations in depth anomaly and seafloor slope.

\subsection{Crustal thickness}

Finally, we consider that the depth anomaly is caused by variations in crustal thickness. This model predicts that the crust over the highest point on the swell (200 at $20 \mathrm{Ma}$ ) is $2.2 \mathrm{~km}$ thicker than the crust at the spreading ridge axis $(-200 \mathrm{~m}$ at $2 \mathrm{Ma})$. First, consider on-ridge variations in crustal production with time. An increase of $50^{\circ} \mathrm{C}$ in an adiabatically decompressing mantle temperature at the rise axis is expected to result in increased partial melt volume with a $5 \mathrm{~km}$ crustal thickness increase [48], so this mechanism is possible. However, we believe it is unlikely to account for the entire $2.2 \mathrm{~km}$ of crustal thickness variation, because such large variations are not observed at high spreading rate ridges [50]. Moreover, the mechanism predicts a symmetrical depth anomaly across the ridge, which is not observed (Fig. 6e). The other possibility is that crustal generation at the ridge axis has remained normal for the past $35 \mathrm{Ma}$ and the depth anomaly is caused by off-axis crustal production, although we do not find a positive correlation between the depth anomaly and the volume of volcanic material corresponding to the Pukapuka Ridges.

\section{Conclusions}

We assessed the magnitude and regional distribution of the depth anomaly on the youngest, eastern section of the proposed 'superswell', away from the influence of recognized nearby hot-spots and the thickened crust of the Tuamotus plateau, where it was expected to grow to over $500 \mathrm{~m}$. Seafloor depths were estimated using the mode of datasets provided by 6 multibeam surveys ( 4 on the west flank of the EPR south of the Marquesas FZ), because the area is characterized by robust volcanism which biases the parametric mean and median estimators. This method accurately estimates seafloor depth even where the majority of seafloor is covered by large constructive 
features. We found that, throughout our survey, the mode was sensitive to seafloor variation while the mean and median were sensitive to the volcanism. Our results suggest that, where there is sufficient swath coverage, the mode estimation technique can provide a more accurate and reliable depth value than the mean and median in areas of robust volcanism and an equally accurate and reliable depth value in areas of flat seafloor.

The depth anomaly, referenced to the plate model [9] was less than $200 \mathrm{~m}$, independent of proximity to a volcanic feature or a gravity lineation trough. The age-related flattening in the original gridded bathymetry (SYNBAPS) was caused by erroneous splining of contour maps, which were regionally unrepresentative of the seafloor depth. The depth anomaly distribution did not show a long-wavelength, age-dependent component, since the anomaly decreases to near-zero for old ages, and the depth anomaly was not bounded by tectonic elements such as the SEPR spreading axis or the Marquesas FZ. The anomalous region of seafloor slope appears to be younger than the mid-Miocene spreading reorientation $(\sim 24 \mathrm{Ma})$, where the average seafloor slope is $218 \mathrm{~m} \mathrm{Myr}^{-1 / 2}$, while older seafloor is subsiding at a near-normal rate $\left(399 \mathrm{~m} \mathrm{Myr}^{-1 / 2}\right)$. After 10 $\mathrm{Ma}$, a similar pattern is developed on a conjugate section of the Nazca Plate, but $250 \mathrm{~m}$ deeper.

The small magnitude of the depth anomaly on the west flank of the SEPR suggests the presence of a weak, subcrustal hot-spot, although none have been identified locally and the Pukapuka Ridges appear to have a non-hot-spot origin. A simple small-scale convection model does not provide sufficient advective heat to the lithosphere to fit the observed shallowing, unless a possible additional thermal perturbation is considered. Variation in crustal thickness, both at the rise axis and, subsequently, due to instantaneous/continuous stretching could account for anomalous seafloor slopes, although a great amount of stretching $(\sim 30 \%)$ is required and normal faulting was not observed in the area. Other models, involving subcrustal intrusive thickening, dynamic support or 'fingering' from a hot-spot in an asthenospheric channel, are still poorly understood. Proper testing of models requiring crustal thickness variation should be accomplished by seismic determination of the Moho depth in the region.

\section{Acknowledgements}

Multibeam and magnetic data for three cruises ARIA02WT, PPTU03WT and TUNE02WT - were available through the Scripps Institution of Oceanography Geological Data Center (SIO-GDC). RC2608 and WEST01MV data were provided generously by Barry Parsons and by Tetsuro Urabe, respectively. WEST04MV data was obtained with funding from the National Science Foundation with the help of David Epp. The authors benefitted from insightful discussions with Andrew Goodwillie, Catherine Johnson, Steve Cande, Jason Phipps-Morgan and Mara Yale, as well as constructive reviews by Norman Sleep, Dan McKenzie and Miriam Kastner. This research was supported by the National Science Foundation, Marine Geology and Geophysics Program (OCE90-19712). [MK]

\section{References}

[1] D.L. Turcotte and E.R. Oxburgh, Finite amplitude convective cells and continental drift, J. Fluid Mech. 28, 29-42, 1967.

[2] J.G. Sclater, R.N. Anderson and M.L. Bell, Elevation of ridges and evolution of the central eastem Pacific, J. Geophys. Res. 76, 7888-7915, 1971.

[3] R.L. Parker and D.W. Oldenburg, Thermal model of ocean ridges, Nature 242, 137-139, 1973.

[4] E.E. Davis and C.R.B. Lister, Fundamentals of ridge crest topography, Earth Planet. Sci. Lett. 21, 405-413, 1974.

[5] M.G. Langseth, X. LePichon and M. Ewing, Crustal structure of the mid-ocean ridges, 5, Heat flow through the Atlantic Ocean floor and convection currents, J. Geophys. Res. 71, 5321-5355, 1966.

[6] D. McKenziz, Some remarks on the development of sedimentary basins, Earth Planet. Sci. Lett. 40, 25-32, 1978.

[7] R.L. Heestand and S.T. Crough, the effect of hot spots on the oceanic age-depth relations, J. Geophys. Res. 86, 6107$6114,1981$.

[8] F.M. Richter and B. Parsons, On the interaction of two scales of convection in the mantle, J. Geophys. Res. 80, 2579. 2541, 1975.

[9] B. Parsons and J.G. Sclater, An analysis of ocean floor bathymetry and heat flow with age, J. Geophys. Res. 82, 803-827, 1977.

[10] H.W. Menard, Depth anomalies and the bobbing motion of drifting islands, J. Geophys. Res. 78, 5128-5137, 1973.

[11] R.S. Detrick, R.P. von Herzen, S.T. Crough, D. Epp, and U. Fehn, Heat flow on the Hawaii Swell and lithospheric reheating, Nature 292, 142-143, 1981.

[12] J. Morgan, Plate motions and deep mantle convection, Mem. Geol. Soc. Am. 132, 7-22, 1972. 
[13] R.S. Detrick and S.T. Crough, Island subsidence, hotspots, and lithospheric thinning, J. Geophys. Res. 83, 1236-1244, 1978.

[14] S.T. Crough, Thermal origin for mid-plate hot-spot swells, Geophys. J. R. Astron. Soc. 55, 451-459, 1978.

[15] S.T. Crough and R.D. Jarrard, the Marquesas-line swell, J. Geophys. Res. 86, 11763-11771, 1981.

[16] J. Mammerickx, Depth anomalies in the Pacific: Active, fossil, and precursor, Earth Planet. Sci. Lett. 53, 147-157, 1981 .

[17] M.K. McNutt and K.M. Fischer, The South Pacific Superswell, in: Seamounts, Islands and Atolls, Am. Geophys. Union, Geophys. Monogr. 43, 25-34, 1987.

[18] M.K. McNutt and A.V. Judge, The Superswell and mantle dynamics beneath the South Pacific, Science 248, 969-975, 1990.

[19] S. Calmant and A. Cazenave, Anomalous elastic thickness of the oceanic lithosphere in the south-central Pacific, Nature 328. 236-238, 1987.

[20] C. DeMets, G.R. Gordon, D.F. Argus and S. Stein, Current plate motions, Geophys. J. Int. 101, 425-578, 1990.

[21] R. Van Wykhouse, SYNBAPS, Tech. Rep. TR-233, Natl. Oceanogr. Off., Washington, DC, 1973.

[22] A.M. Goodwillie and A.B. Watts, An altimetric and bathymetric study of elastic thickness in the central Pacific Ocean. Earth Planet. Sci. Lett. 118, 311-326, 1993.

[23] P.E. Filmer, M.K. McNutt and C.J. Wolfe, Elastic thickness of the lithosphere in the Marquesas and Society Islands, J. Geophys. Res. 98, 19565-19577, 1993.

[24] J.R. Cochran, Variations in subsidence rates along intermediate and fast spreading mid-ocean ridges, Geophys. J. R. Astron. Soc. 87, 421-454, 1986.

[25] D.K. Smith and T.H. Jordan, Seamounts statistics in the Pacific Ocean, J. Geophys. Res. 93, 2899-2918, 1988.

[26] G.A. Abers, B. Parsons and J.K. Weissel, Seamount abundances and distributions in the southeast Pacific, Earth Planet. Sci. Lett. 87, 137-151, 1988.

[27] K.G. Bemis and D.K. Smith, Production of small volcanoes in the Superswell region of the South Pacific, Earth Planet. Sci. Lett. 118, 251-262, 1993.

[28] Y. Shen, D. Forsyth, D.S. Scheirer, and K.C. Macdonald, Two forms of volcanism: Implications for mantle flow and off-axis crustal production on the west flank of the southem East Pacific Rise, J. Geophys. Res. 98, 17,875-17,889, 1993.

[29] D.T. Sandwell, E.L. Winterer, J. Mammerickx, R.A. Duncan, M.A. Lynch, D.A. Levitt and C.L. Johnson, Evidence for diffuse extension of the Pacific Plate from Pukapuka Ridges and Crossgrain gravity lineations, J. Geophys. Res. 100, 15,087-15,099, 1995.

[30] W.H.F. Smith, On the accuracy of digital bathymetric data, J. Geophys. Res. 98, 9591-9603, 1993.

[31] J.C. Marty and A. Cazenave, Regional variations in subsidence rate of oceanic plates; a global analysis, Earth Planet. Sci. Lett. 94, 301-315, 1989.

[32] D.N. Chayes and D.W. Caress, Processing and display of multibeam echosounder data on the $\mathrm{R} / \mathrm{V}$ Maurice Ewing, EOS Trans. Am. Geophys. Union 74, 562, 1993.
[33] S.C. Cande and D.V. Kent, A new geomagnetic polarity time scale for the Late Cretaceous and Cenozoic, J. Geophys. Res. 97, 13917-13951, 1992.

[34] D. Handschumacher, Post-Eocene plate tectonics of the eastem Pacific, Am. Geophys. Union, Geophys. Monogr. 19 , 177-202, 1976.

[35] E.M. Herron, Sea-floor spreading and the Cenozoic history of the East-central Pacific, Geol. Soc. Am. Bull. 83, 1671$1691,1972$.

[36] S.C. Cande, Nazca-South America plate interactions since 50 mybp, in: Peru-Chile trench offshore Peru, Atlas 9. D.M. Hussong, S.P. Dang, L.D. Kulm, R.W. Couch and T.W.C. Hilde, eds., Ocean Margin Drilling Program, Regional Atlas Series, Marine Science International, Woods Hole, MA, Sheet 14, 1986.

[37] R.D. Muller, W.R. Roest, J.-Y. Royer, L.M. Gahagan and J.G. Sclater, A digital age map of the ocean floor, SIO Ref. Ser. 93-30, 1993.

[38] B.W. Silverman, Density Estimation for Statistics and Data Analysis, 175 pp., Chapman and Hall, London, 1986.

[39] J. Mammerickx, R.N. Anderson, H.W. Menard and S.M. Smith, Morphology and tectonic evolution of the East-central Pacific Geol. Soc. Am. Bull. 86, 111-117, 1975.

[40] J. Talandier and E.A. Okal, Crustal structure in the Society and Tuamotu Islands, French Polynesia, Geophys. J. R. Astron. Soc. 88, 499-528, 1987.

[41] L. Fletiout and C. Moriceau, Short-wavelength geoid, bathymetry and the convective pattern beneath the Pacific Ocean, Geophys. J. Int. 110, 6-28, 1992.

[42] N.M. Ribe and U.R. Christensen, Three-dimensional modeling of plume-lithosphere interaction, J. Geophys. Res. 99 , 669-682, 1994.

[43] W.J. Morgan, Rodriguez, Darwin, Amsterdam,..., a second type of hotspot island, J. Geophys. Res. 83, 5355-5360, 1978.

[44] W.F. Haxby and J.K. Weissel, Evidence for small-scalc mantle convection from Seasat altimetric data, J. Geophys. Res. 91, 3507-3520, 1986.

[45] W.R. Buck and E.M. Parmentier, Convection beneath young oceanic lithosphere: Implications for thermal structure and gravity, J. Geophys. Res. 91, 1961-9174, 1986.

[46] E.M. Robinson and B. Parsons, Effect of a shallow lowviscosity zone on small-scale instabilities under the cooling oceanic plates, J. Geophys. Res. 93, 3469-3479, 1988.

[47] A.M. Goodwillie and B. Parsons, Placing bounds on lithospheric deformation in the central Pacific Ocean, Earth Planet. Sci. Lett. 111, 123-129, 1992.

[48] D. McKenzie and M.J. Bickle, The volume and composition of melt generated by extension of the lithosphere, J. Petrol. $29,3,625-679,1988$.

[49] A. Agnon and V. Lyakhovsky, Oceanic topography and heatflow: indications for a silent discharge of cold rock into a convecting earth, Geophys. Res. Lett. 22, 1273-1276, 1995.

[50] Y.J. Chen, Oceanic crustal thickness versus spreading rate, Geophys. Res. Lett. 19, 753-756, 1992. 